\title{
The role of vacuolar ion channels in salt stress tolerance in the liverwort Conocephalum conicum
}

\author{
Mateusz Koselski ${ }^{1}\left[\right.$ Kazimierz Trebacz $^{1}\left[\right.$ [D $\cdot$ Halina Dziubinska ${ }^{1}$
}

Received: 14 November 2018 / Revised: 14 November 2018 / Accepted: 7 May 2019 / Published online: 27 May 2019

(c) The Author(s) 2019

\begin{abstract}
Liverworts are pioneer plants that colonized lands. They had to cope with frequent sea water flooding causing salt stress. The role of vacuoles and in particular slow-activating (SV) channels in the salt stress tolerance was addressed in the present study. A patch-clamp method was used to study sodium fluxes through the tonoplast of the liverwort Conocephalum conicum. The whole-vacuole measurements carried out in a symmetrical $\mathrm{Na}^{+}$concentration allowed recording of slowly activated outward currents typical for SV channels. In a Na${ }^{+}$gradient promoting an efflux of $\mathrm{Na}^{+}$from the vacuole, the outward rectifying properties of SV channels were reduced and inward $\mathrm{Na}^{+}$currents with different inactivation rates were recorded. Single channel analysis proved that a decrease in cytoplasmic $\mathrm{Na}^{+}$concentration evoked an increase in the open probability of the channels and shifted the activation voltages towards negative values. The number of SV channels recorded at negative voltages was dependent on the vacuolar calcium and decreased at the high concentration of this ion in the vacuole. In some of the tested patches, the channels exhibited a flickering type of activity and two different conductance levels. The role of SV channels in $\mathrm{Na}^{+}$accumulation during salt stress and its removal after periods of flooding is discussed in the present paper.
\end{abstract}

Keywords Calcium dependence $\cdot$ Flickering $\cdot$ Patch-clamp $\cdot$ Two-pore channel $\cdot$ Vacuole $\cdot$ Voltage dependence

$\begin{array}{ll}\begin{array}{l}\text { Abbreviations } \\ {\left[\mathrm{Na}^{+} / \mathrm{Ca}^{2+}\right]_{\text {cyt/vac }}}\end{array} & \begin{array}{l}\text { Concentration of sodium/calcium in the } \\ \text { cytoplasm/vacuole }\end{array} \\ \mathrm{SV} & \begin{array}{l}\text { Slowly activating vacuolar channel } \\ \text { TPC1 }\end{array} \\ \text { Two-pore channel 1 }\end{array}$

\section{Introduction}

Vacuoles play multiple roles in plant cell functioning. In terrestrial plants, vacuolar sap constitutes mainly a buffer of water and nutrients in a changing environment. Participation of vacuoles in cellular and long-distance signaling is also

Communicated by J. Kovacik.

Electronic supplementary material The online version of this article (https://doi.org/10.1007/s11738-019-2889-7) contains supplementary material, which is available to authorized users.

Mateusz Koselski

mateusz.koselski@poczta.umcs.lublin.pl

1 Department of Biophysics, Institute of Biology and Biochemistry, Maria Curie-Skłodowska University, Akademicka 19, 20-033 Lublin, Poland of great importance. During the early stages of evolution of terrestrial plants, salt stress was the one of the biggest challenges. Since liverworts are regarded as pioneer plants that colonized lands (Ishizaki 2017), an efficient and quickly operating mechanism of salt stress adaptation in the vacuolar membrane was probably one of the key features of these plants, which allowed them survival of frequent periods of flooding with seawater.

Numerous ion channels have been characterized in the tonoplast with application of electrophysiological methods, mainly the patch-clamp technique. Slowly activated vacuolar channels (SV) are the most abundant ion channels in plant vacuoles; it is therefore not surprising that they were discovered as the first vacuolar channels (Hedrich et al. 1986). SV channels strongly rectify promoting cation (both mono- and divalent) fluxes from the cytosol to the vacuole (reviewed by Pottosin and Schönknecht 2007; Hedrich and Marten 2011; Peiter 2011; Pottosin and Dobrovinskaya 2014; Schönknecht 2013). Recently, the molecular basis of the Arabidopsis TPC1 channel has been recognized (Peiter et al. 2005; Furuichi et al. 2001) and localization of this channel (SV/ TPC1) in the tonoplast has been documented (Peiter et al. 2005). In 2016, the crystallographic structure of these channels from Arabidopsis thaliana has been published (Guo 
et al. 2016; Kintzer and Stroud 2016). A single SV channel protein from A. thaliana (AtTPC1) consists of two tandem shaker-like domains that form a tetrameric channel. In spite of accumulation of data, there is still a debate concerning the physiological role of SV/TPC channels in plants. At a first glance, they look like being designed to be permanently closed. They are activated by an unphysiological cytoplasmic $\mathrm{Ca}^{2+}$ concentration exceeding $10 \mu \mathrm{M}$ (Schulze et al. 2011). A high concentration of luminal calcium (usually present in plant vacuoles) decreases substantially their activity (Pottosin et al. 1997, 2004; Pottosin and Schönknecht 2007; Schönknecht 2013; Beyhl et al. 2009; Koselski et al. 2013). In addition to $\mathrm{Ca}^{2+}, \mathrm{SV} / \mathrm{TPC} 1$ channels are regulated by numerous factors playing roles in cell nutrition and signaling, among them: $\mathrm{Mg}^{2+}, \mathrm{Zn}^{2+}, \mathrm{H}^{+}$, polyamines, dithiothreitol, glutathione, 14-3-3 proteins, heavy metals, phosphorylation/dephosphorylation, calmodulin, and $\mathrm{H}_{2} \mathrm{O}_{2}$ (reviewed by Pottosin and Schönknecht 2007; Hedrich and Marten 2011; Peiter 2011). SV/TPC1 channels can also be considered as putative oxygen sensors (Wang et al. 2017). In this context, publications indicating participation of SV/ TPC1 channels in long-distance electrical signals: actionand variation potentials, throw new light on the role of those channels (Choi et al. 2014; Kiep et al. 2015). It is interesting that salt stress belongs to abiotic stress factors most efficient in evoking propagating signals detected as calcium waves (Choi et al. 2014).

The object of our study Conocephalum conicum belongs to liverworts located evolutionally between algae and higher plants. The gametophyte of $C$. conicum is relatively uniform. It possesses no conducting bundles and no opening and closing stomata as the higher plants do. The thallus is anchored to the soil with rhizoids.

Conocephalum conicum is an excitable plant. It generates single and trains of action potentials, APs, in response to different environmental stimuli (Dziubinska et al. 1983; Trebacz and Zawadzki 1985; Krol and Trebacz 1999; Krol et al. 2003, 2007; Kupisz et al. 2015). It has been reported that SV channels are present in the vacuoles of $C$. conicum (Trębacz and Schönknecht 2000; Trębacz et al. 2007). However, no detailed analysis of these channels has been carried out, in particular, their permeability to $\mathrm{Na}^{+}$has not been addressed.

Here we focus on sodium permeability of SV channels and their possible role in salt stress tolerance. As already mentioned, liverworts, among them Conocephalum, belong to the first land plants (Ishizaki 2017). Before spreading to a "safe" distance from a sea shore, they had to cope with temporary immersion in salty water. It is thus important, from the evolutionary point of view, to know how SV/TPC1 channels adapted to frequent salt stress episodes in the past. In addition to the well-documented situation where the sodium gradient is directed towards the vacuole, which occurs upon flooding, we imposed an opposite $\mathrm{Na}^{+}$gradient mimicking the circumstances after salt removal from the cytosol with sodium ions still abundant in the vacuolar lumen. We characterize inward $\mathrm{Na}^{+}$currents (from the vacuole to the cytosol) and discuss their possible role in salt stress tolerance.

\section{Materials and methods}

\section{Plant material}

Thalli of the liverwort $C$. conicum were collected in a forest near Zwierzyniec (Poland) and then placed together with soil in a vegetative chamber under a photoperiod 16:8 (light:dark), temperature $23{ }^{\circ} \mathrm{C}$, humidity $50-70 \%$, and light intensity of 40-60 $\mu \mathrm{mol} \mathrm{m}^{-2} \mathrm{~s}^{-1}$.

\section{Vacuole isolation}

The vacuoles were isolated according to the previously described non-enzymatic method (Trębacz and Schönknecht 2000). Before the experiment, fragments of a thallus were cut from a rhizoid-free area and plasmolysed by immersion in the bath medium composed of $100 \mathrm{mM}$ Na-gluconate, $2 \mathrm{mM}$ EGTA, $2.09 \mathrm{mM} \mathrm{CaCl}_{2}$ (free calcium concentration was $0.1 \mathrm{mM}$ ), $15 \mathrm{mM}$ HEPES, pH 7 buffered with TRIS and supplemented with $500 \mathrm{mM}$ sorbitol. In the case of the $\mathrm{Na}^{+}$ gradient, $100 \mathrm{mM}$ Na-gluconate was replaced by $10 \mathrm{mM}$ Na-gluconate; in the vacuole-out experiments, no $\mathrm{Ca}^{2+}$ was added and $\mathrm{pH}$ was adjusted to 5.8 with $15 \mathrm{mM}$ MES/TRIS (the other components of the bath solution were unchanged). After 30-60 min incubation, one of the fragments was cut under a drop of a plasmolysing medium with a razor blade and placed in the measuring chamber filled with the bath medium. The osmotic pressure of the bath medium was $300 \mathrm{mOsm} \mathrm{kg}^{-1}$ and this value was adjusted in the symmetrical $\mathrm{Na}^{+}$concentration and $\mathrm{Na}^{+}$gradient by sorbitol. The deplasmolysis of the cells evoked by a decrease in the osmotic pressure caused release of protoplasts through cutoff fragments of the cell walls. After rupture of some of the protoplasts, release of vacuoles was observed.

\section{Patch-clamp experiments}

Patch-clamp experiments were carried out in three configurations - the whole-vacuole, cytoplasm-out, and vacuoleout. The patch pipettes were made from borosilicate tubes (Kwik-Fil TW150-4; WPI, Sarasota, FL, USA) and pulled with a DMZ-Universal Puller (Zeitz-Instruments, Martinsried, Germany). An Ag/AgCl reference electrode was filled with $100 \mathrm{mM} \mathrm{KCl}$ and connected with the solution in the measuring chamber by a ceramic porous bridge. The osmolarity of solutions was measured with a cryoscopic osmometer (Osmomat 030; Gonotec, Berlin, Germany). The ion 
current recordings were made with an EPC-10 amplifier (Heka Elektronik, Lambrecht, Germany) combined with the Patchmaster software (Heka Elektronik). The sampling rate was $10 \mathrm{kHz}$ and the recordings were filtered at $1 \mathrm{kHz}$. The 20-s recordings (Figs. 4, 5, 6) were elaborated by taking every second measuring point. The exchange of the bath solution in the measuring chamber was carried out with a peristaltic pump (ISM796B; Ismatec, Wertheim, Germany). The convention proposed by (Bertl et al. 1992) was used for presentation of the results. In this convention, the vacuolar side of the tonoplast correspond to the extracellular compartment; therefore, positive currents can be carried either by an influx of cations to the vacuole or an efflux of anions from the vacuole. The values of the voltages applied were corrected by the liquid junction potentials that were measured according to the method described by Amtmann and Sanders (1997).

\section{Analysis of the results}

Current density/voltage $(J / V)$ and current/voltage $(I / V)$ characteristics and amplitude histograms were performed in SigmaPlot 9.0 (Systat Software Inc.). The vacuole diameter was used in calculation of the surface of the tonoplast and allowed obtaining the current density $\left(\mathrm{A} / \mathrm{m}^{2}\right)$ of wholevacuole measurements. Fittings of the amplitude histograms by Gaussian peaks were performed in GRAMS/AI 8.0 (Spectroscopy Software). The area under the fitting lines was used for calculation of the average open probability of simultaneously active channels in the patch. The event detection analysis was performed in FitMaster software (Heka Elektronik). It indicated the number of openings (marked on the ordinate) with different time values (marked on the abscissa). The reversal potential $\left(E_{\text {rev }}\right)$ was calculated with the Nernst equation based on the activities of sodium ions. The number of repeats $(n)$ denotes the number of tested vacuoles or tonoplast patches.

\section{Results}

The whole-vacuole recordings carried out on the tonoplast from the liverwort Conocephalum conicum in a symmetrical $100 \mathrm{mM} \mathrm{Na}^{+}$concentration (in the bath and in the pipette) showed slowly activating positive currents (passing from the cytoplasm to the vacuole lumen) typical for SV channels (Slow-activating Vacuolar channels) (Fig. 1a). Tenfold reduction of cytoplasmic $\mathrm{Na}^{+}\left(\left[\mathrm{Na}^{+}\right]_{\text {cyt }}\right)$ changed the voltage dependence of the channels especially by activation of negative currents (Fig. 1b). The current amplitude increments were proportional to the voltage increments and the currents appeared right after the application of the test voltages. Activation of negative currents was time- and voltage-dependent, i.e., the currents appeared instantaneously after application of voltage, and then slow inactivation was recorded. The rate of the inactivation increased together with the magnitude of the negative voltages applied (see inset in Fig. 1b) and was differed in different vacuoles (Online Resource Fig. 1a, b). Moreover, in some recordings after initial inactivation, slow reactivation of negative currents was recorded (Online Resource Fig. 1b, c). Application of the $\mathrm{Na}^{+}$gradient resulted also in appearance of an initial fast phase of activation of positive currents and lowered the rate of the following slow phase (Online Resource Fig. 2b). The current density/voltage curve $(J / V)$ obtained in the $\mathrm{Na}^{+}$gradient calculated from the final part of the traces (80-95\%) crossed the abscissa at $50 \mathrm{mV}$ (Fig. 1c). This value of the reversal potential was close to the value of this parameter $(48 \mathrm{mV})$ obtained from $J / V$ curves calculated from the largest values of the recorded currents (Fig. 1d). The obtained values of the reversal potential were close to the equilibrium potential for $\mathrm{Na}^{+}\left(E_{\mathrm{Na}}=55 \mathrm{mV}\right.$; the activity coefficients of $\mathrm{Na}^{+}$ at $100 \mathrm{mM}$, and $10 \mathrm{mM}$ were 0.87 and 0.75 , respectively) and proved $\mathrm{Na}^{+}$permeability of the channels. The $J / V$ curve showed also a decrease in the negative current density at negative voltages. The maximal value of the current density reached $-0.115 \mathrm{~A} / \mathrm{m}^{2}$ at $-16 \mathrm{mV}$ and decreased to -0.06 $\mathrm{A} / \mathrm{m}^{2}$ at $-85 \mathrm{mV}$. Such changes in the negative current density were not observed in the symmetrical $\mathrm{Na}^{+}$concentration, since the maximal negative current density recorded at $-66 \mathrm{mV}$ amounted to $-0.038 \mathrm{~A} / \mathrm{m}^{2}$ and a similar value $\left(0.035 \mathrm{~A} / \mathrm{m}^{2}\right)$ was recorded at $-100 \mathrm{mV}$.

The voltage dependence and permeability of the channels were also studied by application of two types of measuring protocols allowing analysis of the whole vacuole tail currents. The first one allowed observation of the kinetics of the currents preceded by activation of SV channels by positive voltage (Fig. 2a, b), and the second one showed tail currents after initial activation of the channels by negative voltage (Fig. 2d, e). Traces (a) and (d) represent SV currents at a symmetrical $\mathrm{Na}^{+}$concentration, whereas traces (b) and (e) were recorded at the $\mathrm{Na}^{+}$gradient $(100 \mathrm{mM}$ in the vacuole and $10 \mathrm{mM}$ in the cytoplasm). The analysis of tail currents in both types of measuring protocols confirmed the $\mathrm{Na}^{+}$-permeability of the channels, since the $J / V$ curves (calculated from the initial or final part of tail currents from the first and the second type of measuring protocol, respectively) obtained after reduction of $\left[\mathrm{Na}^{+}\right]_{\text {cyt }}$ were shifted to positive values and crossed the abscissa close to $E_{\mathrm{Na}}$ (Fig. 2c, f). In respect to the voltage dependence, the most visible effect of the reduction of $\left[\mathrm{Na}^{+}\right]_{\text {cyt }}$ was the slowdown of the inactivation rate of the channels that was observed after transition of the voltage from positive to negative values (compare final part of Fig. 2a, b, see also Online Resource Fig. 2a) and from 0 or $15 \mathrm{mV}$ to negative voltages (compare the initial part of Fig. 2d, e). The second type of the measuring protocol 
Fig. 1 Whole-vacuole $\mathrm{Na}^{+}$currents flowing through SV channels from the liverwort Conocephalum conicum. a Example of recordings obtained in a symmetrical (in the patch pipette and in the bath) $100 \mathrm{mM}$ concentration of $\mathrm{Na}^{+}$. The pipette contained $100 \mathrm{mM} \mathrm{Na}-$ gluconate, 2 mM EGTA, 15 mM MES, pH 5.8 buffered by TRIS and the bath-100 mM Na-gluconate, $2 \mathrm{mM}$ EGTA, $2.09 \mathrm{mM} \mathrm{CaCl}_{2}$ (free calcium concentration was $0.1 \mathrm{mM}$ ), $15 \mathrm{mM}$ HEPES, pH 7 buffered by TRIS. b Recordings obtained at the Na-gluconate concentration in the bath lowered to $10 \mathrm{mM}$. The expanded part of the traces show differences in the current levels obtained at voltages between 15 and $-85 \mathrm{mV}$. c Current density/voltage dependences calculated from the final part of the traces (80-95\%) obtained in the symmetrical $100 \mathrm{mM}$ $\mathrm{Na}$-gluconate concentration as in $\mathbf{a}$ (closed circles, $n=11$ ) and in tenfold reduced Na-gluconate in the bath as in $\mathbf{b}$ (open circles, $n=13$ ). d Current density/voltage dependences calculated from the largest current value obtained in the symmetrical $100 \mathrm{mM}$ Na-gluconate concentration as in a (closed circles, $n=8$ ) and in tenfold reduced Na-gluconate in the bath as in $\mathbf{b}$ (open circles, $n=11$ ). Points on the curves $\mathbf{c}$ and $\mathbf{d}$ correspond to the mean \pm standard error. At the top of recordings $\mathbf{a}$ and $\mathbf{b}$, the measuring protocols are shown, which indicate that the recordings were carried out by application of a $0.5 \mathrm{~s}$ holding voltage $(0 \mathrm{mV}$ for a and $15 \mathrm{mV}$ for $\mathbf{b})$, then $3 \mathrm{~s}$ test voltages with $20 \mathrm{mV}$ steps (from 100 to $-100 \mathrm{mV}$ for a and from 115 to $-85 \mathrm{mV}$ for $\mathbf{b}$, and $0.3 \mathrm{~s}$ voltage $(0 \mathrm{mV}$ for $\mathbf{a}$ and $15 \mathrm{mV}$ for $\mathbf{b})$. The arrow indicates the reversal potential for $\mathrm{Na}^{+}$. Time gap between successive voltage passes equaled $2.2 \mathrm{~s}$

also showed that the reduction of $\left[\mathrm{Na}^{+}\right]_{\text {cyt }}$ evoked slowly activated negative currents, which was especially observed after transition from $-65 \mathrm{mV}$ to voltages more negative than $55 \mathrm{mV}$ (Fig. 2e, f). The slowly activated negative currents increased disproportionally to the voltage increments and were reduced at negative voltages (inset in Fig. 2e). A similar phenomenon was observed in the final part of slowly inactivated inward currents (inset in Fig. 1b) and in the final part of inactivation of negative currents in Fig. $2 b$. The results proved that, in the gradient of $\mathrm{Na}^{+}$promoting an efflux of this ion from the vacuole, the negative $\mathrm{Na}^{+}$currents exhibit a slow rate of inactivation and activation. The process of activation of negative currents can be dependent on the time of application of negative voltage-during the first $2-3 \mathrm{~s}$ the currents inactivate and then slow activation is observed (Fig. 2e, see also Online Resource Fig. 1b, c).

The features of the currents recorded in the whole-vacuole configuration were confirmed in the cytoplasm-out recordings of the single channel activity (Fig. 3). A characteristic trait of the recordings obtained in the symmetrical $\mathrm{Na}^{+}$concentration was the time- and voltage-dependent activity of SV channels recorded at positive voltages and the lack of the channel activity at negative voltages (Fig. 3a). The most visible effects evoked by the reduction of $\left[\mathrm{Na}^{+}\right]_{\text {cyt }}$ from 100 to $10 \mathrm{mM}$ were the openings of SV channels recorded right after the application of negative voltage, and the different rates of inactivation dependent on the test voltage (Fig. 3b). The kinetics of the channel inactivation was similar as in the case of the whole-vacuole currents and was dependent on the value of negative voltage; the more negative voltages were
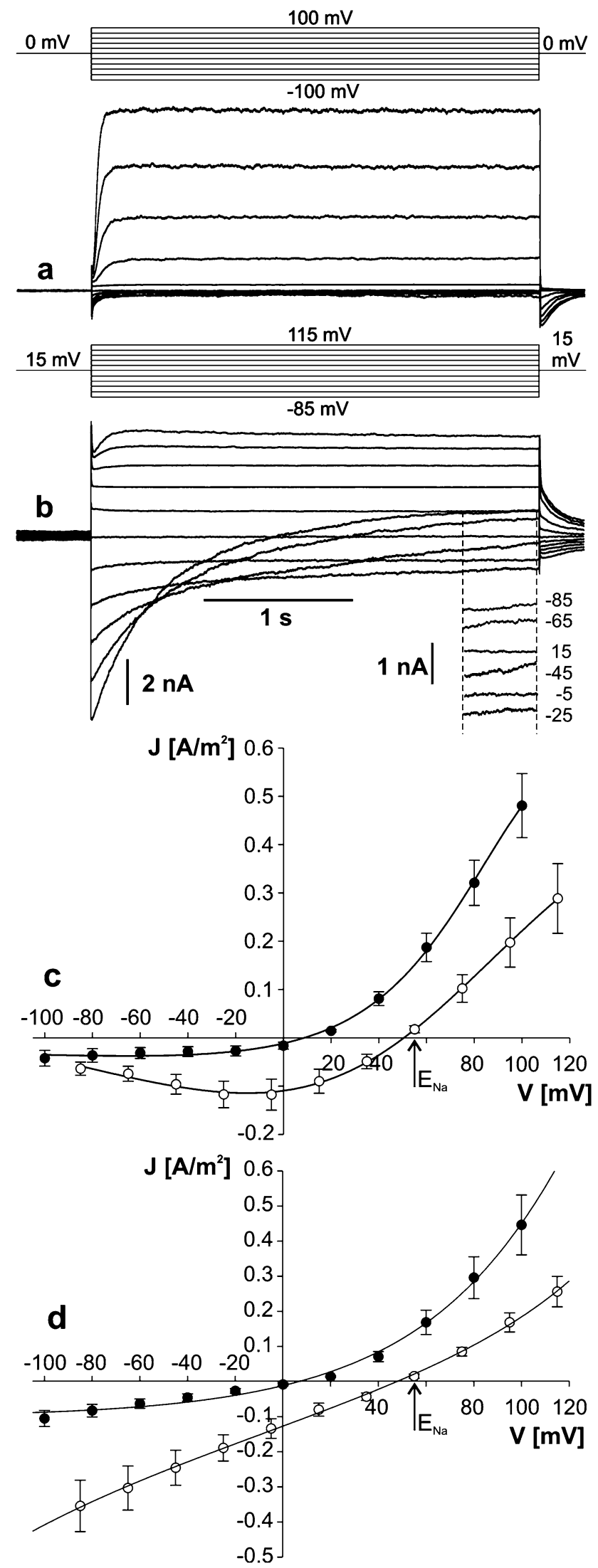

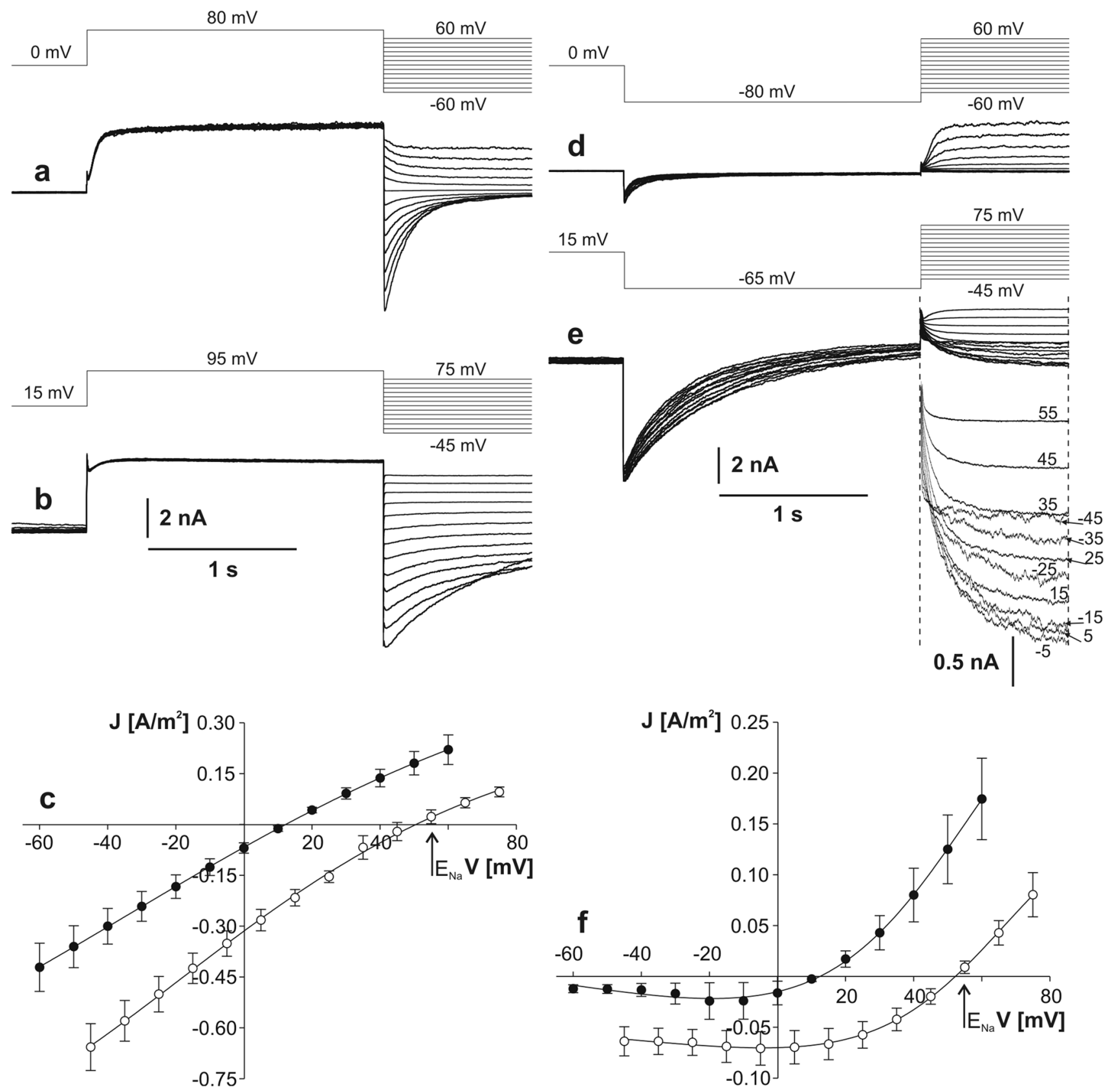

Fig. 2 Whole-vacuole tail currents recorded after initial activation of outward currents $(\mathbf{a}-\mathbf{c})$ and activation of inward currents $(\mathbf{d}-\mathbf{f})$. a, $\mathbf{d}$ Tail currents recorded in the symmetrical concentration of $\mathrm{Na}^{+}$ in conditions as in Fig. 1a. b, e Tail currents recorded after tenfold reduction of $\mathrm{Na}^{+}$in the bath (as in Fig. 1b). The expanded part of the traces in e show differences in the current levels obtained at voltages between 55 and $-45 \mathrm{mV}$. c, f Current density/voltage characteristics $(\mathrm{J} / \mathrm{V})$ obtained from instantaneous (c) and steady-state part of tail currents (f) recorded after activation of outward currents [as in a (closed circles, $n=5$ ) and $\mathbf{b}$ (open circles, $n=6)$ ] and inactivation of inward currents [as in $\mathbf{d}$ (closed circles, $n=5$ ) and $\mathbf{e}$ (open circles, $n=5$ )], respectively. The values of the current used for the $J / V$ curves were

calculated from the extreme recorded during the first $0.1 \mathrm{~s}$ after activation of SV channels (for $\mathbf{a}, \mathbf{b}$ ) and from the mean obtained during last $0.1 \mathrm{~s}$ of tails (for $\mathbf{d}, \mathbf{e}$ ). Points on curves $\mathbf{a}, \mathbf{b}, \mathbf{d}$ and $\mathbf{e}$ correspond to the mean \pm standard error. At the top of obtained recordings $\mathbf{a}, \mathbf{b}$, $\mathbf{d}$ and $\mathbf{e}$, the measuring protocols are shown, which indicate that the currents were evoked by application of $0.5 \mathrm{~s}$ holding voltage $(0 \mathrm{mV}$ for $\mathbf{a}, \mathbf{d}$ and $15 \mathrm{mV}$ for $\mathbf{b}, \mathbf{e})$, then $2 \mathrm{~s}$ activation of outward currents $(80 \mathrm{mV}$ for $\mathbf{a}, 95 \mathrm{mV}$ for $\mathbf{b})$ or inward currents $(-80 \mathrm{mV}$ for $\mathbf{d}$ and $-65 \mathrm{mV}$ for e), and $1 \mathrm{~s}$ of voltages with $10 \mathrm{mV}$ steps (from -60 to $60 \mathrm{mV}$ for $\mathbf{a}, \mathbf{d}$ and from -45 to 75 for $\mathbf{b}, \mathbf{e}$ ). Time gap between successive voltage passes equaled $1.5 \mathrm{~s}$ 


\section{a}

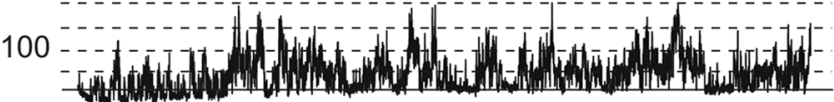

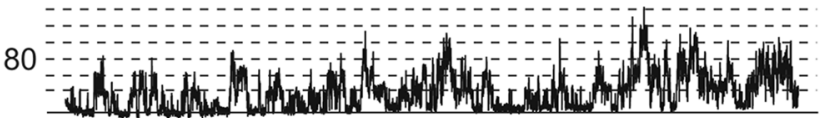

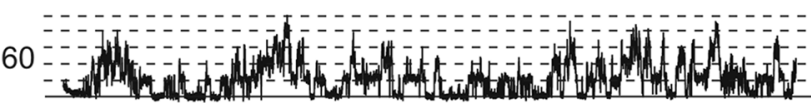

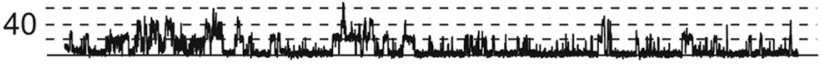

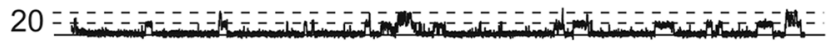

0
-20
-40
-60
-80 85 65 45 25 - 5 5 - nam 1

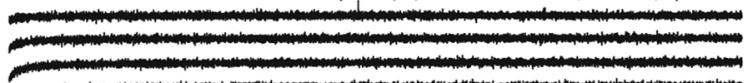
d 80 60 -

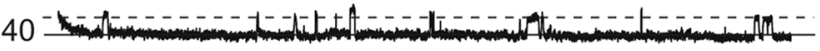

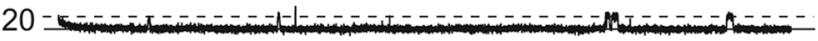
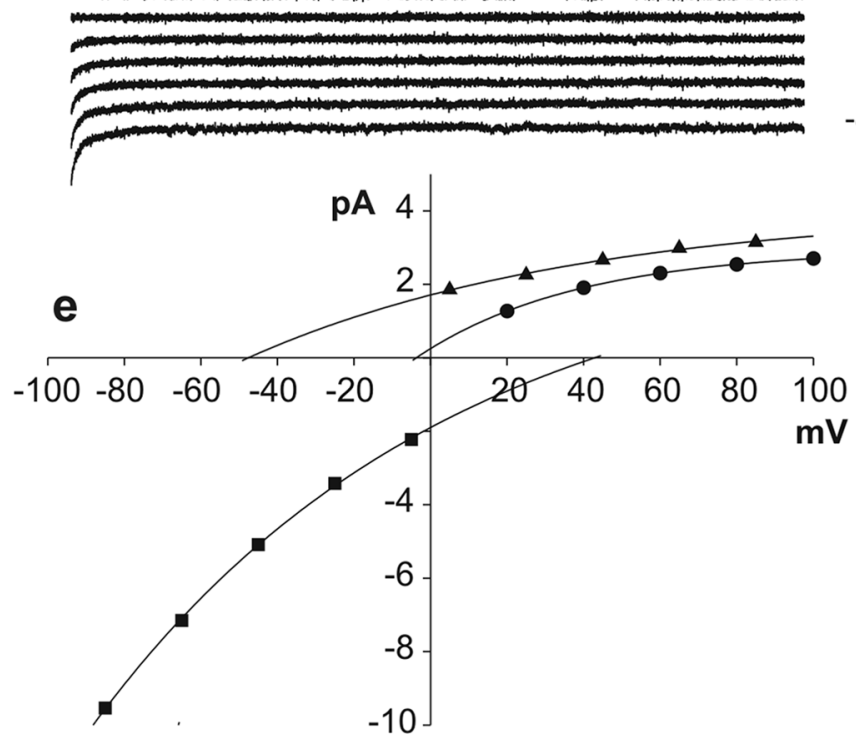
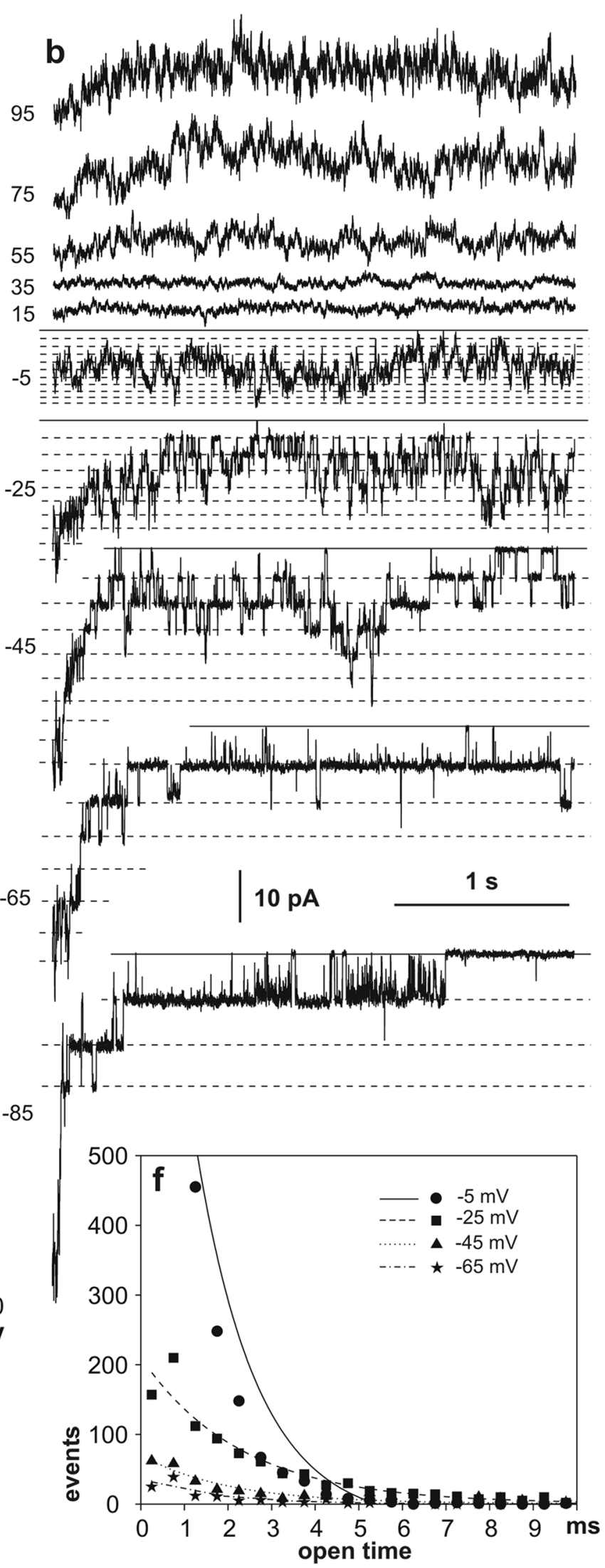
4Fig. $3 \mathrm{Na}^{+}$currents flowing through single SV channels from the liverwort Conocephalum conicum. a, b Cytoplasm-out recordings obtained in the symmetrical $100 \mathrm{mM}$ concentration of Na-gluconate (as in Fig. 1a) and after tenfold reduction of Na-gluconate in the bath (as in Fig. 1b), respectively. The solid line indicates the close state of the channels and the dashed lines denote the open states. The values of holding voltages in $\mathrm{mV}$ are indicated on the left side of the traces. c, d Vacuole-out recordings obtained in the Na-gluconate gradient promoting a $\mathrm{Na}^{+}$influx to the vacuole (the bath contained $10 \mathrm{mM} \mathrm{Na}$ gluconate, $2 \mathrm{mM}$ EGTA, $15 \mathrm{mM}$ MES, pH 5.8 buffered by TRIS and the pipette-100 mM Na-gluconate, $2 \mathrm{mM}$ EGTA, $2.09 \mathrm{mM} \mathrm{CaCl}_{2}$ (free calcium concentration was $0.1 \mathrm{mM}$ ), $15 \mathrm{mM}$ HEPES, $\mathrm{pH} 7$ buffered by TRIS) and after application of symmetrical $100 \mathrm{mM}$ Nagluconate, respectively. e $I / V$ curves obtained from the recordings in a (circles), b (squares), and c (triangles). f Event detection analysis obtained from the traces obtained at negative voltages in $\mathbf{b}$. The values of voltages at which the obtained traces were analyzed are indicated

applied, the faster the decrease in the number of the active channels was observed. The event detection analysis indicated that, together with more negative voltages, the number of short (less than $5 \mathrm{~ms}$ ) openings decreased (Fig. 3f). The recordings of the channel activity obtained at positive voltages did not allow distinguishing the open states of single channels, probably due to the increase in the number of active channels together with the decrease in the channel conductance. The measurements carried out in the vacuoleout and cytoplasm-out configuration and with application of different directions of the $\mathrm{Na}^{+}$gradient through the tonoplast helped to prepare single channel $I / V$ curves, which indicate $\mathrm{Na}^{+}$permeability of the channels, as in the whole-vacuole configuration (Fig. 3e).

The effects of the reduction of $\left[\mathrm{Na}^{+}\right]_{\text {cyt }}$ on the single channel activity were tested by application of long lasting (20 s) steps of negative voltage (Fig. 4a). Together with the time from the application of the $\mathrm{Na}^{+}$gradient an increase in the open probability was recorded, which reached a maximum after over a dozen of minutes. Moreover, with time, an increase in the number of active channels and a decrease in their conductance were also recorded, which often occurs when there are many active channels in one patch. In accordance with the amplitude histograms, the conductance of individual channels active in the patch was dependent on the number of simultaneously active channels. For instance, 6 min after the reduction of $\left[\mathrm{Na}^{+}\right]_{\text {cyt }}$, the conductance of "the 3rd channel" obtained from the distance between the 4th (the lowermost) and 3th (the upper) maxima of the Gaussian peaks amounted to $128 \mathrm{pS}$ and reached $152 \mathrm{pS}$ for "the 1 st channel". A much more pronounced difference in the channel conductance was obtained after $12 \mathrm{~min}$ from the reduction of $\left[\mathrm{Na}^{+}\right]_{\mathrm{cyt}}-68 \mathrm{pS}$ for "the 7th channel" and 136 pS for "the 1st channel".

To study if the SV channel activity depends on the direction of the $\mathrm{Na}^{+}$gradient, measurements were carried out in the vacuole-out configuration. In this configuration, the number of active channels was usually lower than in the cytoplasm-out configuration (probably caused by the smaller surface of the tested patches) and was similar in the different concentrations of vacuolar $\mathrm{Na}^{+}\left[\mathrm{Na}^{+}\right]_{\text {vac }}$ (Figs. 3c, d, $4 b)$. Long lasting recordings proved a slight influence of the $\left[\mathrm{Na}^{+}\right]_{\mathrm{vac}}$ decrease on the open probability of SV channels, from 0.02 recorded at $40 \mathrm{mV}$ in the symmetrical $\mathrm{Na}^{+}$ concentration to 0.03 recorded at $45 \mathrm{mV}$ after the tenfold reduction of $\left[\mathrm{Na}^{+}\right]_{\text {vac }}$ (Fig. 4b).

In some of tested patches, the channels recorded after the reduction of $\left[\mathrm{Na}^{+}\right]_{\text {cyt }}$ exhibited two different types of activities-bursts of activity during which flickering type transitions between open and closed states were recorded (recorded in 6 out of the 23 tested patches; Fig. 5a) and supraconductance states of openings which, according to the amplitude histogram, reached $142 \%$ (176 pS at $-25 \mathrm{mV}$ ) of the standard conductance obtained for "the 1st channel" (124 pS at $-25 \mathrm{mV}$ ) (recorded in 5 out of the 23 tested patches; Fig. 5b). The event detection analysis indicated that the opening times of channels exhibiting bursts of activity are higher than in the typical activity of the channels (Fig. 5a inset).

Since inhibition of SV channel activity by vacuolar calcium is a frequently described phenomenon (Pottosin et al. 1997, 2004; Pottosin and Schönknecht 2007; Schönknecht 2013; Beyhl et al. 2009; Koselski et al. 2013), we decided to study the effect of application of high $1 \mathrm{mM} \mathrm{Ca}^{2+}$ from the vacuolar side of the membrane during the vacuole-out recordings (Fig. 6). It was especially interesting to examine if in conditions similar to the physiological ones, i.e., a high vacuolar and low cytoplasmic concentration of $\mathrm{Ca}^{2+}$, $\mathrm{SV}$ channels are still capable of release of $\mathrm{Na}^{+}$from the vacuole. The measurements carried out in the $\mathrm{Na}^{+}$gradient facilitating an efflux of this ion from the vacuole proved that the increase in vacuolar $\mathrm{Ca}^{2+}$ did not completely block the inward $\mathrm{Na}^{+}$currents, although a decrease in the number of simultaneously active channels was observed in such conditions (Fig. 6). The results have proved that both the gradient of $\mathrm{Na}^{+}$and the vacuolar calcium can regulate the activity of SV channels and that these channels can be a route of $\mathrm{Na}^{+}$ escape from the vacuole after initial reduction of the sodium level in the cytosol.

\section{Discussion}

Typical for SV channels are slowly activated outwardly rectifying currents carried by monovalent ions, including $\mathrm{Na}^{+}$, and divalent ions. Permeability of SV channels to $\mathrm{Na}^{+}$ opens the question of the role of these channels in salt stress adaptation. Participation of SV channels in $\mathrm{Na}^{+}$sequestration inside the vacuole is possible, among others, because of their rectification-towards the vacuole. Here we focus 

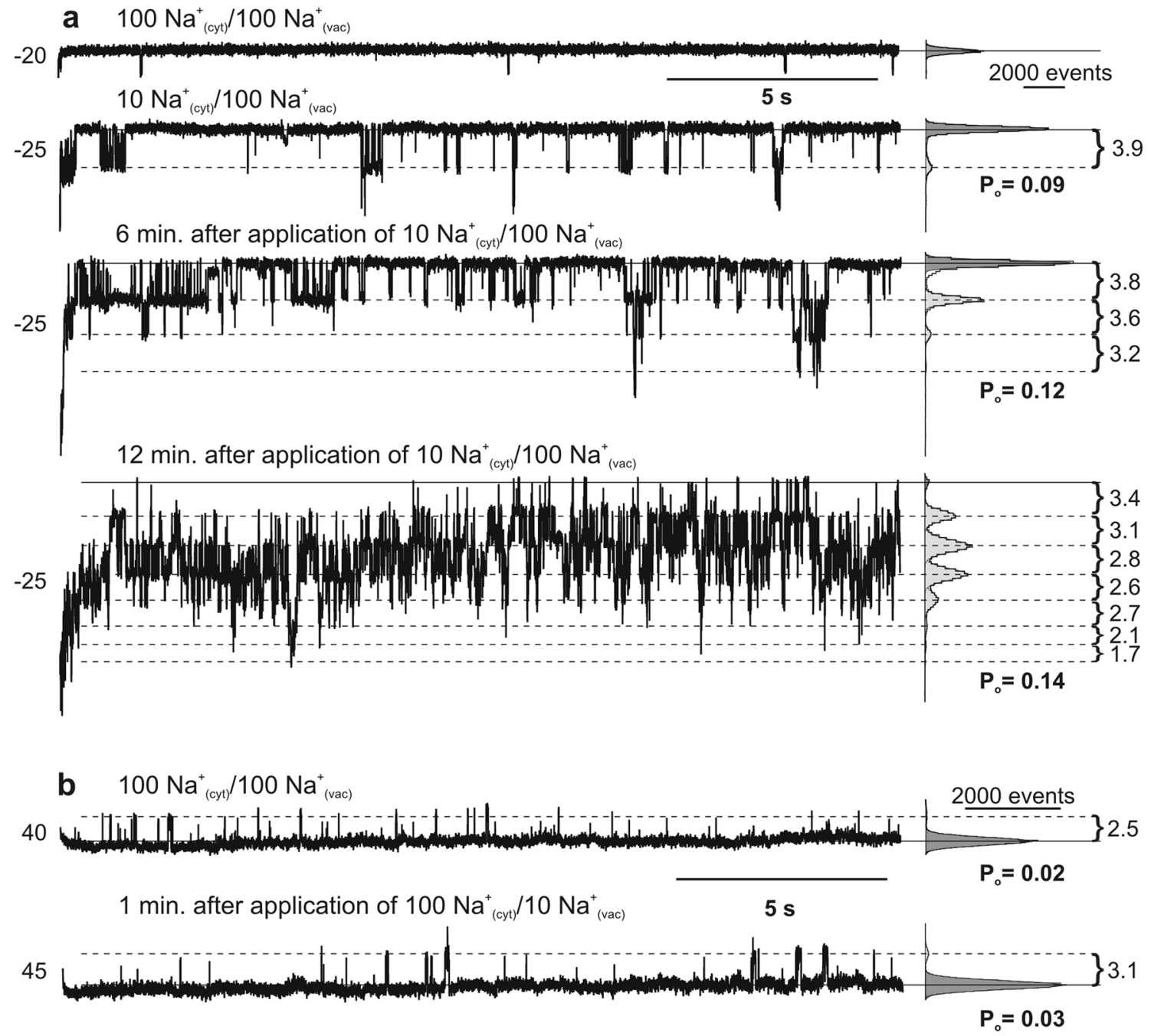

Fig. 4 Effects of reduction of the cytoplasmic (a) and vacuolar (b) $\mathrm{Na}^{+}$concentration on SV channel activity. (a) Cytoplasm-out recordings obtained in the symmetrical $100 \mathrm{mM} \mathrm{Na}^{+}$concentrations (upper trace; as in Fig. 1a) and after reduction of cytoplasmic $\mathrm{Na}^{+}$to $10 \mathrm{mM}$ (lower traces; as in Fig. 1b). The amplitude histograms elaborated for each trace present the current amplitude (distances between horizontal dashed lines in $\mathrm{pA}$ ) events (horizontal bar) and the aver- age open probability of simultaneously active channels in the patch $\left(P_{\mathrm{o}}\right)$. b Vacuole-out recordings obtained in the symmetrical $100 \mathrm{mM}$ $\mathrm{Na}^{+}$concentrations (upper trace as in Fig. 2d) and after reduction of the vacuolar $\mathrm{Na}^{+}$concentration to $10 \mathrm{mM}$ (lower trace; as in Fig. 2c). The values of holding voltages in $\mathrm{mV}$ are indicated on the left side of the traces on their possible role in sodium release from the vacuole under an electrochemical potential gradient favoring $\mathrm{Na}^{+}$ influx to the cytosol. Currents carried by $\mathrm{K}^{+}$and $\mathrm{Mg}^{2+}$ were recorded in earlier patch-clamp studies of SV channels in C. conicum (Trębacz et al. 2007; Trębacz and Schönknecht 2000), although sodium permeability and their possible role in salt stress have not been addressed. SV-type currents were also recorded in plants closely related with Conocephalum - the liverwort Marchantia polymorpha $\left[\mathrm{K}^{+}\right.$currents; (Koselski et al. 2017)] and the moss Physcomitrella patens $\left[\mathrm{Na}^{+}, \mathrm{K}^{+}, \mathrm{Mg}^{2+}\right.$ and $\mathrm{Ca}^{2+}$ currents; (Koselski et al. 2013, 2015)]. Another important feature of SV channels is their calcium dependence. The study of calcium dependence of
SV channels in Physcomitrella indicated a way of regulation characteristic for this kind of channels. The channels were active in the presence of cytoplasmic calcium, whose threshold concentration depended on vacuolar calcium - the lower $\left[\mathrm{Ca}^{2+}\right]_{\mathrm{vac}}$, the lower $\left[\mathrm{Ca}^{2+}\right]_{\text {cyt }}$ was needed for SV channel activation (Koselski et al. 2013). In the present study, to optimize the conditions for $\mathrm{SV}$ channel recordings, we applied $0.1 \mathrm{mM}\left[\mathrm{Ca}^{2+}\right]_{\text {cyt }}$ (a concentration commonly used in SV channel studies) and no $\mathrm{Ca}^{2+}$ was added to the vacuolar side. Moreover, to avoid the activity of different channels than SV, like potassium selective VK channels found, for example, in the moss Physcomitrella (Koselski et al. 2013) or anion permeable channels recorded earlier in Conocephalum (Trębacz 


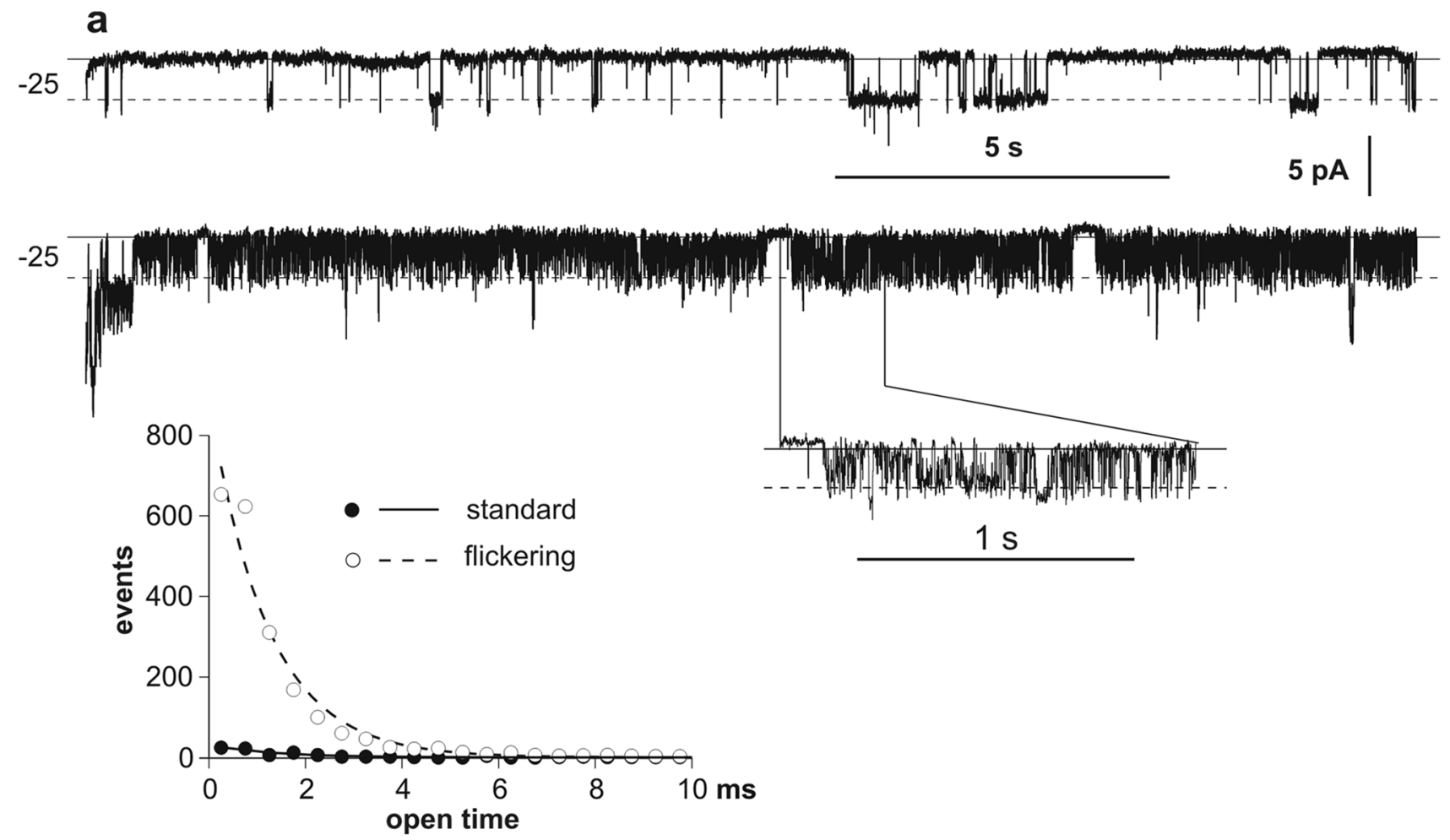

\section{b}
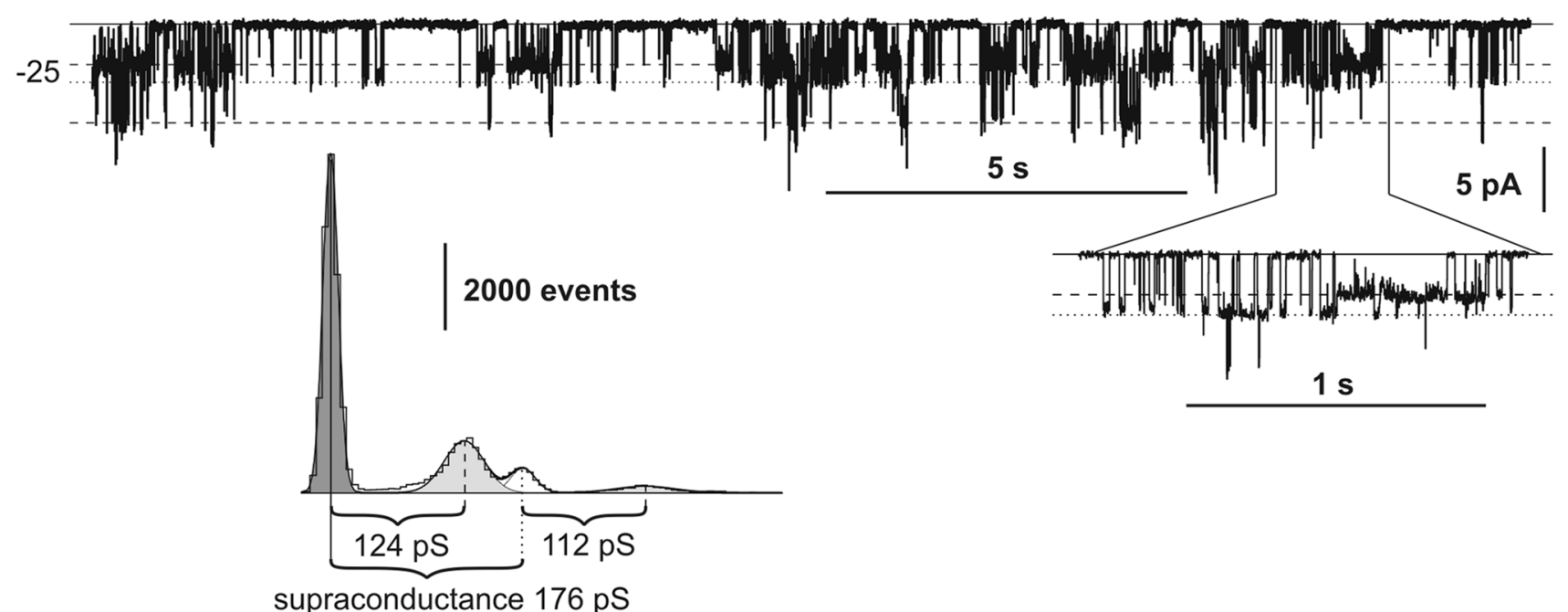

Fig. 5 Two types of SV channel activity. a Standard type of activity (upper trace) and flickering type of activity (lower trace) recorded in the same patch. The recordings were obtained in the cytoplasm-out configuration in the $\mathrm{Na}^{+}$gradient promoting an efflux of this ion from the vacuole (conditions as in Fig. 1b). The event detection analysis shows differences between the open times of standard activity (closed circles and solid line) and the flickering type of activity (open cir-

et al. 2007), we carried our measurements in the presence of $\mathrm{Na}^{+}$ions as the only cations passable through SV channels and gluconate, which is impermeable to anion channels.

Partial disruption of the basic ability of the SV channels-outward rectification, which was manifested by the cles and dashed line). b Two different conductance levels recorded in the same conditions as in $\mathbf{a}$. The dashed line indicates the open state of the channel and the dotted line-the supraconductance level of the channel. The Gauss fittings created for the amplitude histogram show standard conductance (light gray area under the fitting line) and supraconductance (white area) of the channel. All recordings were obtained at $-25 \mathrm{mV}$

occurrence of inward currents (Fig. 1b) was recorded in the SV channels from Conocephalum. In our previous work, outward rectifying properties at the same $\mathrm{Na}^{+}$gradient were exhibited in the SV channels from Physcomitrella, but the measurements were carried out in the presence of the 


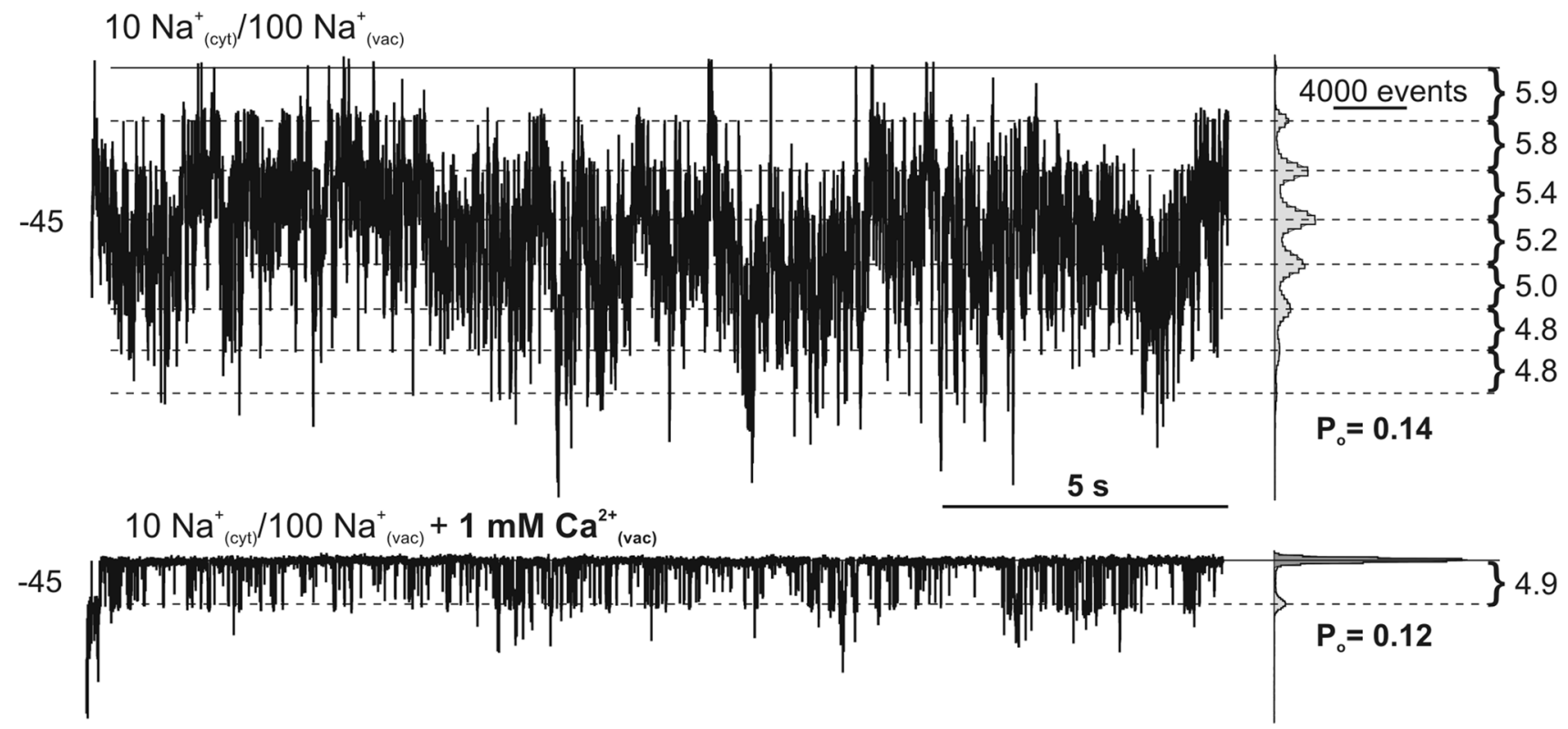

Fig. 6 Dependence of inward $\mathrm{Na}^{+}$currents on vacuolar calcium. The vacuole-out recordings were obtained at $-45 \mathrm{mV}$ in the symmetrical $\mathrm{Na}^{+}$concentration without vacuolar $\mathrm{Ca}^{2+}$ (upper trace; as in Fig. 2c), and after application of $1 \mathrm{mM} \mathrm{Ca}^{2+}$ to the bath (lower trace;

vacuolar $\mathrm{Ca}^{2+}$ concentration that could inhibit the channel activity (Koselski et al. 2013). In a higher plant A. thaliana, despite the lack of vacuolar calcium, $\mathrm{K}^{+}$but not $\mathrm{Na}^{+}$inward currents were carried by SV channels; moreover, luminal $\mathrm{Na}^{+}$inhibited the channel activity by shifting their voltage dependence to more positive values (Ivashikina and Hedrich 2005). On the other hand, the time and voltage dependence of inward currents from Arabidopsis was similar to that in our study. Both currents decreased with the magnitude of the applied negative voltages and, when preceded by a negative voltage, where slowly activated [compare Fig. 2e with the whole-vacuole traces from Arabidopsis obtained after reduction of the $\mathrm{K}^{+}$concentration in the bath-Fig. $2 \mathrm{~b}$, c from Ivashikina and Hedrich (2005)]. In fact, SV channels from Arabidopsis exhibit some differences in the permeability of inward currents depending on cell type since, in contrast to the above discussed results obtained from suspension cell culture, the SV channels from the guard cells were able to carry $\mathrm{Na}^{+}$inward currents (Rienmüller et al. 2010). The rise in inward currents carried by SV channels in Arabidopsis can be dependent on the conserved putative plant TPC1 fragment of an amino acid cluster (D454) located in the vacuolar loop connecting transmembrane domain 7 with 8 (Bonaventure et al. 2007). The point mutation of D454 (also known as fou 2 mutation) impairs recognition of luminal calcium by SV channels and enhances the activity of inward $\mathrm{K}^{+}$currents in the presence of this ion in the vacuole (Beyhl et al. 2009). Inward $\mathrm{K}^{+}$currents in the presence of vacuolar the calcium concentration was obtained by mixing $2 \mathrm{mM}$ EGTA and $2.99 \mathrm{mM} \mathrm{CaCl} 2$ ). The amplitude histograms elaborated for each trace are described in the same way as in Fig. 4

calcium were also recorded in wild-type SV channels from barley and appeared after reduction of the cytoplasmic $\mathrm{K}^{+}$ concentration from 50 to $20 \mathrm{mM}$ (Hedrich et al. 1986).

An interesting feature of the SV channels from Conocephalum demonstrated in the single channel analysis carried out at negative voltages was the existence of two different conductance levels and bursts of flickering type of the channel activity (Fig. 5). Flickering of SV channels was previously described in different plants, but this phenomenon was always connected with disturbance of the channel activity evoked by application of different ion channel inhibitors. The flickering type of activity was recorded in M. polymorpha after application of ruthenium red-an inhibitor of calcium channels (Koselski et al. 2017). The same inhibitor evoked flickering of SV channels from Beta vulgaris recorded at high positive voltages (higher than about $50 \mathrm{mV}$ ) and in the presence of ruthenium red at a concentration lower $(0.1-1 \mu \mathrm{M})$ than necessary for complete blockage of the channels (3-5 $\mu \mathrm{M})$ (Pottosin et al. 1999). Flickering of SV channels was also recorded in A. thaliana after application of an antibiotic neomycin known among others from inhibition of calcium- and cation-permeable channels (Scholz-Starke et al. 2006). Another feature of channels from Conocephalum, i.e., two different conductance levels, was documented, among others, in outwardly rectifying $\mathrm{K}^{+}$channels from barley (Kolb et al. 1987). The voltage dependence of these channels was similar to that in SV channels, whose activity and slow kinetics of activation 
were confirmed by other whole-vacuole studies carried out on barley (van den Wijngaard et al. 2001; Bethke and Jones 1997; Pottosin et al. 1997).

The physiological role of the possibility of an efflux of $\mathrm{Na}^{+}$from the vacuole through SV channels described in this study can be considered in respect to calcium dependence of these channels. The plant vacuole is a storage of calcium and accumulates this ion at different concentrations, e.g., $200 \mu \mathrm{M}$ in Beta vulgaris (Perez et al. 2008) and Eremosphaera viridis (Bethmann et al. 1995) or 2.3 and $1.5 \mathrm{mM}$ in the liverwort Riccia fluitans and Zea mays (Felle 1988), respectively. A decrease in the open probability of SV channels together with an increase in $\left[\mathrm{Ca}^{2+}\right]_{\text {vac }}$ was recorded in barley (Pottosin et al. 1997). In the same study, inward slowly activating $\mathrm{K}^{+}$currents were shown, but only in the presence of a high cytoplasmic concentration of $\mathrm{Ca}^{2+}$ (from 0.5 to $2 \mathrm{mM}$ ) and in the absence of this ion in the vacuole. In our study, we demonstrated that the application of $1 \mathrm{mM}$ vacuolar $\mathrm{Ca}^{2+}$ reduced the number of active $\mathrm{SV}$ channels but did not completely inhibit the inward $\mathrm{Na}^{+}$currents carried by the channels (Fig. 6). Taking into account an increase of the open probability at less negative voltages than those applied in this experiment $(-45 \mathrm{mV})$ and also the fact that the values of the potential difference across the tonoplast in plant vacuoles are usually between 0 and $-30 \mathrm{mV}$ (Walker et al. 1996; Bethmann et al. 1995), it is probable that SV channels in Conocephalum can be considered as a route for release of $\mathrm{Na}^{+}$from the vacuole.

Compartmentation of $\mathrm{Na}^{+}$into the vacuole is one of the strategies for alleviation of the deleterious effects of an excess cytoplasmic $\mathrm{Na}^{+}$concentration. Participation of $\mathrm{SV}$ channels in uptake and storage of $\mathrm{Na}^{+}$into the vacuole would be possible only in the case of maintenance of the outward rectifying properties by these channels for $\mathrm{Na}^{+}$ currents. Involvement of SV channels in salinity tolerance was previously widely studied in halophytes-salt tolerant plants that store a high concentration of $\mathrm{Na}^{+}$ions in the vacuole. One of the first studies carried out on Suaeda maritima pointed to lack of special adaptation of SV channels in this extreme halophyte (Maathuis et al. 1992). On the other hand, the latter study carried out on another halophyte-Chenopodium quinoa indicated that the activity of SV channels is lowered in salt-grown plants, which was recorded only in old leaves (Bonales-Alatorre et al. 2013b). Such negative control of SV channels (together with reduction of the activity of fast activated channels, FV) is postulated to be responsible for reduction of $\mathrm{Na}^{+}$ leak from the vacuole and efficient sequestration of this ion in the vacuole. These observations were supplemented by further studies carried out on $C$. quinoa genotypes with different salt tolerance (Bonales-Alatorre et al. 2013a). In the salt-sensitive genotype, salinity induced a shift of the threshold of SV channel activation to more positive voltages and, as a result, a tenfold decrease in the mean SV channel activity was recorded at physiological tonoplast potentials. A lower ability of SV channel activity reduction under salinity was observed in the salt-tolerant genotype, since the threshold of the channel activation in the saltgrown plants was only slightly changed.

In Conocephalum, similar as in other plants, the main role in compartmentation of $\mathrm{Na}^{+}$into the vacuole and detoxification of the cell can be played by NHX exchangers, which are so far the best known proteins taking part in these processes (Yamaguchi et al. 2013; RodriguezRosales et al. 2009; Blumwald et al. 2000). The NHX protein characterized in Arabidopsis (AtNHX1) utilizes the $\mathrm{H}^{+}$gradient as a driving force and mediates the low affinity of the $\mathrm{K}^{+} / \mathrm{H}^{+}$and $\mathrm{Na}^{+} / \mathrm{H}^{+}$antiport (Venema et al. 2002). The $\mathrm{Na}^{+}$and $\mathrm{K}^{+}$selectivity of AtNHX1 is regulated by interaction of calmodulin-like protein (AtCam15) with the C-terminal tail located in the vacuolar lumen and is dependent on vacuolar $\mathrm{Ca}^{2+}$ and $\mathrm{pH}-\mathrm{a}$ high $\mathrm{Ca}^{2+}$ concentration and acidic $\mathrm{pH}$ favor $\mathrm{K}^{+}$over $\mathrm{Na}^{+}$fluxes (Yamaguchi et al. 2005). Despite high $\left[\mathrm{Ca}^{2+}\right]_{\text {vac }}$ occurring in the plant vacuole, selectivity of AtNHX1 to $\mathrm{Na}^{+}$instead of $\mathrm{K}^{+}$is possible, because an increase in vacuolar $\mathrm{pH}$ occurs during salinity stress (Nakamura et al. 1992; Gruwel et al. 2001; Okazaki et al. 1996; Katsuhara et al. 1989) and can cause release of AtCam15 from the C-terminal tail of AtNHX1 (Yamaguchi et al. 2005).

Conocephalum conicum belongs to liverworts, which were in a front line of plants that conquered lands. It is possible that $C$. conicum preserved a mechanism allowing survival in a frequently flooded environment at a sea shore at the beginning of its expansion to the lands. The mechanism of the release of $\mathrm{Na}^{+}$from the vacuole demonstrated in this study may serve removal of the excess of this ion after the salt stress and subsequent expelling $\mathrm{Na}^{+}$from the cytoplasm to the extracellular space by plasma membrane sodium transport mechanisms. This would create a sodium gradient similar to that applied in our study.

Author contribution statement $\mathrm{KM}$ conceived and designed the research, carried out the experiments, analysed the data, made the figures, and wrote the main part of the manuscript. TK received the Grant from the NCN (National Science Centre) no. 2013/09/B/NZ1/01052, participated in writing, and reviewed the manuscript. DH participated in part of the experiments and reviewed the manuscript. All authors have read and approved the final version of the manuscript.

Acknowledgements This work was supported by NCN (National Science Centre) Grant no. 2013/09/B/NZ1/01052. 


\section{Compliance with ethical standards}

Conflict of interest The authors declare that they have no conflict of interest.

Open Access This article is distributed under the terms of the Creative Commons Attribution 4.0 International License (http://creativeco mmons.org/licenses/by/4.0/), which permits unrestricted use, distribution, and reproduction in any medium, provided you give appropriate credit to the original author(s) and the source, provide a link to the Creative Commons license, and indicate if changes were made.

\section{References}

Amtmann A, Sanders D (1997) A unified procedure for the correction of liquid junction potentials in patch clamp experiments on endo- and plasma membranes. J Exp Bot 48:361-364. https://doi. org/10.1093/jxb/48.Special_Issue.361

Bertl A, Blumwald E, Coronado R, Eisenberg R, Findlay G, Gradmann $\mathrm{D}$ et al (1992) Electrical measurements on endomembranes. Science 258(5084):873-874

Bethke PC, Jones RL (1997) Reversible protein phosphorylation regulates the activity of the slow-vacuolar ion channel. Plant J. 11(6):1227-1235. https://doi.org/10.1046/j.1365313X.1997.11061227.x

Bethmann B, Thaler M, Simonis W, Schönknecht G (1995) Electrochemical potential gradients of $\mathrm{H}^{+}, \mathrm{K}^{+}, \mathrm{Ca}^{2+}$, and $\mathrm{Cl}^{-}$across the tonoplast of the green alga Eremosphaera viridis. Plant Physiol 109(4):1317-1326

Beyhl D, Hörtensteiner S, Martinoia E, Farmer EE, Fromm J, Marten I, Hedrich R (2009) The fou 2 mutation in the major vacuolar cation channel TPC1 confers tolerance to inhibitory luminal calcium. Plant J. 58(5):715-723. https://doi.org/10.1111/j.1365313X.2009.03820.X

Blumwald E, Aharon GS, Apse MP (2000) Sodium transport in plant cells. BBA Biomembr 1465(1-2):140-151. https://doi. org/10.1016/s0005-2736(00)00135-8

Bonales-Alatorre E, Pottosin I, Shabala L, Chen ZH, Zeng FR, Jacobsen SE et al (2013a) Differential activity of plasma and vacuolar membrane transporters contributes to genotypic differences in salinity tolerance in a halophyte species, Chenopodium quinoa. Int J Mol Sci 14(5):9267-9285. https://doi.org/10.3390/ijms1 4059267

Bonales-Alatorre E, Shabala S, Chen ZH, Pottosin I (2013b) Reduced tonoplast fast-activating and slow-activating channel activity is essential for conferring salinity tolerance in a facultative halophyte, quinoa. Plant Physiol 162(2):940-952. https://doi. org/10.1104/pp.113.216572

Bonaventure G, Gfeller A, Proebsting WM, Hortensteiner S, Chetelat A, Martinoia E et al (2007) A gain-of-function allele of TPC1 activates oxylipin biogenesis after leaf wounding in Arabidopsis. Plant J 49(5):889-898. https://doi.org/10.1111/j.1365313X.2006.03002.X

Choi WG, Toyota M, Kim SH, Hilleary R, Gilroy S (2014) Salt stress-induced $\mathrm{Ca}^{2+}$ waves are associated with rapid, long-distance root-to-shoot signaling in plants. Proc Natl Acad Sci USA 111(17):6497-6502. https://doi.org/10.1073/pnas.1319955111

Dziubinska H, Paszewski A, Trebacz K, Zawadzki T (1983) Electrical activity of the liverwort Conocephalum conicum: the all-ornothing law, strength-duration relation, refractory periods and intracellular potentials. Physiol Plant 57(2):279-284. https://doi. org/10.1111/j.1399-3054.1983.tb00911.x
Felle H (1988) Cytoplasmic free calcium in Riccia fluitans L. and Zea mays L.: Interaction of $\mathrm{Ca}^{2+}$ and $\mathrm{pH}$ ? Planta 176(2):248-255. https://doi.org/10.1007/bf00392452

Furuichi T, Cunningham KW, Muto S (2001) A putative two pore channel AtTPC1 mediates $\mathrm{Ca}^{2+}$ flux in Arabidopsis leaf cells. Plant Cell Physiol 42(9):900-905. https://doi.org/10.1093/pcp/pce145

Gruwel MLH, Rauw VL, Loewen M, Abrams SR (2001) Effects of sodium chloride on plant cells; a ${ }^{31} \mathrm{P}$ and ${ }^{23} \mathrm{Na}$ NMR system to study salt tolerance. Plant Sci 160(5):785-794. https://doi. org/10.1016/s0168-9452(00)00424-6

Guo JT, Zeng WZ, Chen QF, Lee C, Chen LP, Yang Y et al (2016) Structure of the voltage-gated two-pore channel TPC1 from Arabidopsis thaliana. Nature 531(7593):196-201. https://doi. org/10.1038/nature 16446

Hedrich R, Marten I (2011) TPC1-SV channels gain shape. Mol Plant 4(3):428-441. https://doi.org/10.1093/mp/ssr017

Hedrich R, Flügge UI, Fernandez JM (1986) Patch-clamp studies of ion transport in isolated plant vacuoles. FEBS Lett 204(2):228-232. https://doi.org/10.1016/0014-5793(86)80817-1

Ishizaki K (2017) Evolution of land plants: insights from molecular studies on basal lineages. Biosci Biotechnol Biochem 81(1):7380. https://doi.org/10.1080/09168451.2016.1224641

Ivashikina N, Hedrich R (2005) $\mathrm{K}^{+}$currents through SV-type vacuolar channels are sensitive to elevated luminal sodium levels. Plant $\mathrm{J}$ 41(4):606-614. https://doi.org/10.1111/j.1365-313X.2004.02324 .X

Katsuhara M, Kuchitsu K, Takeshige K, Tazawa M (1989) Salt stressinduced cytoplasmic acidification and vacuolar alkalization in Nitellopsis obtusa cells-in vivo ${ }^{31} \mathrm{P}$-nuclear magnetic resonance study. Plant Physiol 90(3):1102-1107. https://doi.org/10.1104/ pp.90.3.1102

Kiep V, Vadassery J, Lattke J, Maass JP, Boland W, Peiter E et al (2015) Systemic cytosolic $\mathrm{Ca}^{2+}$ elevation is activated upon wounding and herbivory in Arabidopsis. New Phytol 207(4):996-1004. https:// doi.org/10.1111/nph.13493

Kintzer AF, Stroud RM (2016) Structure, inhibition and regulation of two-pore channel TPC1 from Arabidopsis thaliana. Nature 531(7593):258-264. https://doi.org/10.1038/nature17194

Kolb HA, Köhler K, Martinoia E (1987) Single potassium channels in membranes of isolated mesophyll barley vacuoles. J Membr Biol 95(2):163-169. https://doi.org/10.1007/bf01869161

Koselski M, Trebacz K, Dziubinska H (2013) Cation-permeable vacuolar ion channels in the moss Physcomitrella patens: a patchclamp study. Planta 238(2):357-367. https://doi.org/10.1007/ s00425-013-1902-4

Koselski M, Dziubinska H, Seta-Koselska A, Trebacz K (2015) A nitrate-permeable ion channel in the tonoplast of the moss Physcomitrella patens. Planta 241(5):1207-1219. https://doi. org/10.1007/s00425-015-2250-3

Koselski M, Trebacz K, Dziubinska H (2017) Vacuolar ion channels in the liverwort Marchantia polymorpha: influence of ion channel inhibitors. Planta 245(5):1049-1060. https://doi.org/10.1007/ s00425-017-2661-4

Krol E, Trebacz K (1999) Calcium-dependent voltage transients evoked by illumination in the liverwort Conocephalum conicum. Plant Cell Physiol 40(1):17-24

Krol E, Dziubinska H, Trebacz K (2003) Low-temperature induced transmembrane potential changes in the liverwort Conocephalum conicum. Plant Cell Physiol 44(5):527-533. https://doi. org/10.1093/pcp/pcg070

Krol E, Dziubińska H, Trębacz K, Koselski M, Stolarz M (2007) The influence of glutamic and aminoacetic acids on the excitability of the liverwort Conocephalum conicum. J Plant Physiol 164(6):773-784. https://doi.org/10.1016/j.jplph.2006.04.015

Kupisz K, Trebacz K, Gruszecki WI (2015) Menthol-induced action potentials in Conocephalum conicum as a result of unspecific 
interactions between menthol and the lipid phase of the plasma membrane. Physiol Plant 154(3):349-357. https://doi.org/10.1111/ ppl.12288

Maathuis FJM, Flowers TJ, Yeo AR (1992) Sodium-chloride compartmentation in leaf vacuoles of the halophyte Suaeda-maritima (L.) Dum and its relation to tonoplast permeability. J Exp Bot 43(254):1219-1223. https://doi.org/10.1093/jxb/43.9.1219

Nakamura Y, Ogawa T, Kasamo K, Sakata M, Ohta E (1992) Changes in the cytoplasmic and vacuolar $\mathrm{pH}$ in intact cells of mung bean root-tips under high- $\mathrm{NaCl}$ stress at different external concentrations of $\mathrm{Ca}^{2+}$ ions. Plant Cell Physiol 33(7):849-858

Okazaki Y, Kikuyama M, Hiramoto Y, Iwasaki N (1996) Shortterm regulation of cytosolic $\mathrm{Ca}^{2+}$, cytosolic $\mathrm{pH}$ and vacuolar $\mathrm{pH}$ under $\mathrm{NaCl}$ stress in the charophyte alga Nitellopsis obtusa. Plant Cell Environ 19(5):569-576. https://doi. org/10.1111/j.1365-3040.1996.tb00390.x

Peiter E (2011) The plant vacuole: emitter and receiver of calcium signals. Cell Calcium 50(2):120-128. https://doi.org/10.1016/j. ceca.2011.02.002

Peiter E, Maathuis FJM, Mills LN, Knight H, Pelloux J, Hetherington $\mathrm{AM}$ et al (2005) The vacuolar $\mathrm{Ca}^{2+}$-activated channel TPC1 regulates germination and stomatal movement. Nature 434(7031):404408. https://doi.org/10.1038/nature03381

Perez V, Wherrett T, Shabala S, Muniz J, Dobrovinskaya O, Pottosin I (2008) Homeostatic control of slow vacuolar channels by luminal cations and evaluation of the channel-mediated tonoplast $\mathrm{Ca}^{2+}$ fluxes in situ. J Exp Bot 59(14):3845-3855. https://doi. org/10.1093/jxb/ern225

Pottosin I, Dobrovinskaya O (2014) Non-selective cation channels in plasma and vacuolar membranes and their contribution to $\mathrm{K}^{+}$transport. J Plant Physiol 171(9):732-742. https://doi. org/10.1016/j.jplph.2013.11.013

Pottosin II, Schönknecht G (2007) Vacuolar calcium channels. J Exp Bot 58(7):1559-1569. https://doi.org/10.1093/jxb/erm035

Pottosin II, Tikhonova LI, Hedrich R, Schönknecht G (1997) Slowly activating vacuolar channels can not mediate $\mathrm{Ca}^{2+}$-induced $\mathrm{Ca}^{2+}$ release. Plant J 12(6):1387-1398

Pottosin II, Dobrovinskaya OR, Muniz J (1999) Cooperative block of the plant endomembrane ion channel by ruthenium red. Biophys J 77(4):1973-1979

Pottosin I, Martinez-Estevez M, Dobrovinskaya O, Muniz J, Schönknecht $\mathrm{G}$ (2004) Mechanism of luminal $\mathrm{Ca}^{2+}$ and $\mathrm{Mg}^{2+}$ action on the vacuolar slowly activating channels. Planta 219(6):1057-1070. https://doi.org/10.1007/s00425-004-1293-7

Rienmüller F, Beyhl D, Lautner S, Fromm J, Al-Rasheid KAS, Ache P et al (2010) Guard cell-specific calcium sensitivity of high density and activity SV/TPC1 channels. Plant Cell Physiol 51(9):15481554. https://doi.org/10.1093/pcp/pcq102

Rodriguez-Rosales M, Galvez FJ, Huertas R, Aranda MN, Baghour M, Cagnac O et al (2009) Plant NHX cation/proton antiporters. Plant Signal Behav 4(4):265-276
Scholz-Starke J, Carpaneto A, Gambale F (2006) On the interaction of neomycin with the slow vacuolar channel of Arabidopsis thaliana. J Gen Physiol 127(3):329-340. https://doi.org/10.1085/jpg.20050 9402

Schönknecht G (2013) Calcium signals from the vacuole. Plants (Basel) 2(4):589-614. https://doi.org/10.3390/plants2040589

Schulze C, Sticht H, Meyerhoff P, Dietrich P (2011) Differential contribution of EF-hands to the $\mathrm{Ca}^{2+}$-dependent activation in the plant two-pore channel TPC1. Plant J 68(3):424-432. https://doi. org/10.1111/j.1365-313X.2011.04697.X

Trębacz K, Schönknecht G (2000) Simple method to isolate vacuoles and protoplasts for patch-clamp experiments. Protoplasma 213(1-2):39-45

Trebacz K, Zawadzki T (1985) Light-triggered action potentials in the liverwort Conocephalum conicum. Physiol Plant 64(4):482-486. https://doi.org/10.1111/j.1399-3054.1985.tb08526.x

Trębacz K, Schönknecht G, Dziubińska H, Hanaka A (2007) Characteristics of anion channels in the tonoplast of the liverwort Conocephalum conicum. Plant Cell Physiol 48(12):1747-1757. https ://doi.org/10.1093/pcp/pcm147

van den Wijngaard PWJ, Bunney TD, Roobeek I, Schönknecht G, de Boer AH (2001) Slow vacuolar channels from barley mesophyll cells are regulated by 14-3-3 proteins. FEBS Lett 488(1-2):100 104. https://doi.org/10.1016/s0014-5793(00)02394-2

Venema K, Quintero FJ, Pardo JM, Donaire JP (2002) The Arabidopsis $\mathrm{Na}^{+} / \mathrm{H}^{+}$exchanger AtNHX1 catalyzes low affinity $\mathrm{Na}^{+}$and $\mathrm{K}^{+}$ transport in reconstituted liposomes. J Biol Chem 277(4):24132418. https://doi.org/10.1074/jbc.M105043200

Walker DJ, Leigh RA, Miller AJ (1996) Potassium homeostasis in vacuolate plant cells. Proc Natl Acad Sci USA 93(19):10510-10514. https://doi.org/10.1073/pnas.93.19.10510

Wang FF, Chen ZH, Shabala S (2017) Hypoxia sensing in plants: on a quest for ion channels as putative oxygen sensors. Plant Cell Physiol 58(7):1126-1142. https://doi.org/10.1093/pcp/pcx079

Yamaguchi T, Aharon GS, Sottosanto JB, Blumwald E (2005) Vacuolar $\mathrm{Na}^{+} / \mathrm{H}^{+}$antiporter cation selectivity is regulated by calmodulin from within the vacuole in a $\mathrm{Ca}^{2+}-$ and $\mathrm{pH}$-dependent manner. Proc Natl Acad Sci USA 102(44):16107-16112. https://doi. org/10.1073/pnas.0504437102

Yamaguchi T, Hamamoto S, Uozumi N (2013) Sodium transport system in plant cells. Front Plant Sci 4:410. https://doi.org/10.3389/ fpls.2013.00410

Publisher's Note Springer Nature remains neutral with regard to jurisdictional claims in published maps and institutional affiliations. 